\title{
Chronic Stress and Its Symptoms among Mexican Immigrants in Edmonton, Canada
}

\author{
Elizabeth Pozos-Radillo*, Lourdes Preciado-Serrano, Ana Plascencia-Campos, \\ Luis Zaragoza-Perales \\ University Center for Health Sciences at the University of Guadalajara, Guadalajara, México \\ Email: "litaemx@yahoo.com.mx
}

Received 15 March 2016; accepted 19 July 2016; published 22 July 2016

Copyright (C) 2016 by authors and Scientific Research Publishing Inc.

This work is licensed under the Creative Commons Attribution International License (CC BY). http://creativecommons.org/licenses/by/4.0/

c) (i) Open Access

\begin{abstract}
Immigration-related stress is the result of an environment that imposes demands surpassing the psychological resources of those suffering from it with a destabilizing effect on their physical and psychological health. The purpose of this study is to determine what the chronic stress levels are and their association with psychophysiological symptoms and gender in Mexican immigrants living in Edmonton, Canada. A representative random sample was made of 237 immigrants in 2012. The stress symptoms inventory was used and a multiple regression and multivariate analysis was made. Results indicated that chronic stress levels were: $14 \%$ high, $46 \%$ medium and $40 \%$ low and psychophysiological predictor symptoms were: fatigue, constipation, frequent colds, cold hands and feet and insomnia, and the female gender. Therefore one may conclude that a precise identification of the predictor symptoms of chronic stress may help promote and implement programs aimed at timely prevention of stress before they affect the health and occupational safety of Mexican immigrants living in Edmonton, Canada.
\end{abstract}

\section{Keywords}

Emigrants and Immigrants, Psychological Stress, Mexico, Canada

\section{Introduction}

Migrations in the XXI century constitute an increasingly more pertinent topic for research and clinical care due to the fact that they trigger a series of psychosocial stressors and their association with mental health. The migratory process produces high levels of stress linked to psychopathology with a destabilizing effect on physical and psychological health [1].

"Corresponding author.

How to cite this paper: Pozos-Radillo, E., Preciado-Serrano, L., Plascencia-Campos, A. and Zaragoza-Perales, L. (2016) Chronic Stress and Its Symptoms among Mexican Immigrants in Edmonton, Canada. Journal of Behavioral and Brain Science, 6, 295-304. http://dx.doi.org/10.4236/jbbs.2016.68029 
The growing levels of poverty in Mexico have resulted in increasingly more Mexicans emigrating to other countries in search of a better life and one of the most significant increases of the movement of people has been to Canada in recent years [2]. Immigration is characterized by sudden changes to the physical and economic environment as well as the social environment, such as the loss of family and friends [3], the language barrier and integration into a new culture [4] in which immigrants may display mental and somatic symptoms brought on by immigration and stress [5].

Some studies have already established the immigration process as responsible for triggering adaptation mechanisms that create stress [6] [7]. They mention that immigrant women are the ones who face more stress factors and who have fewer support resources to cope with them [8] [9].

Stress may take place when a person perceives that his or her resources are scarce and insufficient to cope with the demands of the environment. In this regard immigrants may experience the characteristics of acculturative stress if they fail to adapt. This occurs when people experience adverse physical and emotional reactions as the result of the complex adjustment they must make in an unfamiliar cultural context. This is when stress emerges from the tension experienced when contrasting the values and customs of their own culture in a different cultural context [10].

The research carried out by Spitzer (2009) [11] on the immigration experience in Canada points out that although it is voluntary, it is associated with stress due to the social problems and political imagination suffered by immigrants and refugees as well as the acculturation process they are subjected to. This way stress is mediated by the immigrant's ability to take advantage of individual, cultural and material resources to withstand adaptation and integration efforts.

The "transactional-cognitive model" proposed by Lazarus in 1996 [12], fundamental in stress research, proposed a definition of stress focused on the interaction between the person and his or her surroundings. In this regard he proposed an assessment process of the organism aiming in two parallel directions, towards the environment and towards one's own resources. The key to this model lies in the cognitive assessment of the stimuli as well as the response [13].

The goal of this study was: to determine what the chronic stress levels are and their association with psycho physiological symptoms and gender in Mexican immigrants living in Edmonton, Canada.

\section{Methods}

The study was cross-sectional and associative. We asked the Mexican Society of Edmonton, Canada for the number of immigrants they had registered up to August, 2012 to ascertain the sample size and the result was 2809.

\subsection{Sample}

The sample was computed with Epi6 software where a frequency of 56\% was considered [14]; 46\% was taken to be a minimum acceptable frequency with an accuracy level of $99.9 \%$ [15], which resulted in a total sample number of 237 individual interviews.

The population was selected by a simple random technique by means of a table of random numbers, selecting them from the registration list until completing the total sample. The purpose of the project was explained to them and they were asked for authorization to locate them in person at their homes to answer the survey.

The inclusion criteria were Mexican immigrants living in Edmonton, Canada for 6 months or more, from any emigration place of origin, older than 18, from both genders, and that were registered at the Mexican Society of Edmonton, Canada, and that they would answer the survey applied in Spanish.

The study took place during 2012. The research protocol and the informed consent form were reviewed and approved by the Ministry of Health of Jalisco with reference number CI/19610 pursuant to the 1975 Declaration of Helsinki regarding the ethics of research with human beings.

\subsection{Instrumentation}

The Stress Symptoms Inventory SSI [16] was used to obtain the levels as well as the psychophysiological symptoms of chronic stress. Its adaptation for Mexico is a Chronbach's Alpha of 0.80 . The questionnaire, consisting of a list of 41 characteristic stress symptoms, offered scaled answers from one to six points: 1 ("never") 
and 6 (“always"), and the participant indicated his or her feelings during the previous six months, allowing us to obtain the levels of chronic stress.

Classification into high, medium and low levels was done using the average and standard deviation (SD); a high level was considered above two or three SD, a medium level ( \pm one SD) and a low level (less than two and three SD).

Frequency of each symptom was classified according to the score selection: high between 5 - 6, medium between 3 - 4, and low between 1 - 2 .

The psychological symptoms of chronic stress were: feeling depressed, angry outbursts, overwhelming need to run and hide, a strong desire to cry, inability to concentrate, feeling tied down, nervous tics, easily startled, nervous laugh, stuttering, feeling anxiety, the urge to eat constantly, insomnia, increased daily dosage of tranquilizers, increased alcohol consumption, nightmares, increased daily consumption of cigarettes, accident proneness, and an overwhelming need to move constantly.

The physical symptoms of chronic stress were: increased heart rate, dry-mouth, weakness-dizziness, fatigue, teeth-grinding, clenched jaw, stress-related headaches, migraines, excessive sweating, frequent need to urinate, indigestion, stomachache, neck and shoulder pain, loss of appetite, constipation, frequent colds, cold hands and feet, allergies, gastritis, colitis, high blood pressure and tremors. Gender was also recorded and was considered a productive variable in multiple regression.

\subsection{Data Collection and Analysis}

There were two stages of the analysis; the first one was by means of descriptive statistics of frequency and percentage.

The second stage looked for risk associations by estimating Odds Ratio (OR) with a C.I. of $95 \%$ and a significance level $(p<0.05)$. The statistical analysis was performed individually for each of the psychophysiological stress symptoms with a high stress level (SSI). The bivariate associations were traced consecutively for this purpose by analyzing the contingency tables where the chronic stress levels were assessed (high, medium and low) for each of the psychophysiological symptoms (SSI) and were converted into dichotomies.

Nuisance variables were controlled with a multivariate analysis through logistical regression. Upon finding an association between several psychophysiological stress symptoms and high stress levels (SSI) that could interact as confounding variables, the nuisance effect was controlled and an adjusted association measure was estimated to prevent it from altering any evaluation of the results.

The bivariate associations were traced consecutively for this purpose by analyzing the contingency tables. Chronic stress levels (high, medium and low) and psychophysiological stress symptoms (SSI) were assessed and converted into dichotomies with values of $0-1$. High level and high frequency were taken to be risks.

An analysis was made of the Pearson correlation to accurately specify information about the predictive value and to determine the effectiveness of the measurements obtained. A step regression analysis was made for the dependent chronic stress variable and the predictive variables by simultaneously introducing an equation of measurements at a significance level $(p<0.05)$. The variables appeared in order in the equation in these analyses in terms of the percentage of the explained variance.

A hierarchical multiple regression analysis was later applied to determine the predictive value of the psychophysiological symptoms with respect to high level chronic stress, from where the increased variance value was obtained.

The data were tabulated and processed in the SPSS (IBM ${ }^{\circledR}$ SPSS $^{\circledR}$ Statistics 20, USA 1989-2011) statistics package under the university's license.

\section{Results}

Two hundred thirty-seven Mexican immigrants living in Edmonton, Canada were interviewed to make this study: 119 (50.2\%) women and 118 (49.8\%) men. Ages ranged from 18 to 48 years old with an average of 32.71 ( \pm 9.67$)$ years old. Time of residence in Canada ranged from 1 to 17 years with an average of $7.57( \pm 2.46)$ years.

The descriptive analysis of high, medium and low levels of chronic stress with regards to psychophysiological symptoms and gender showed that 14\% (34) had high levels, of which $23(10 \%)$ were women and 11 (5\%) men; the most frequent physical symptom being neck and back pain with 34 (13\%) and the least frequent being excessive sweating with 5 (2\%). The most frequent physical symptom among the female gender was: neck and 
back pain with 23 (10\%), followed by the symptoms of loss of appetite with 21 (9\%), stomachache and increased cigarette consumption with 18 (7\%), frequent colds, teeth grinding, clenched jaw, frequent need to urinate and stress-related headaches, all of them with 17 (7\%), insomnia, constipation and increased heart rate with 12 (5\%), dry-mouth, colitis and indigestion with 11 (4\%), migraine, high blood pressure, gastritis and tremors with 6 (3\%) and excessive sweating. Except for the symptom of weakness-dizziness that was more frequent in the male gender with $11(4 \%)$, the symptoms of fatigue with $11(4 \%)$, cold hands and feet with $6(3 \%)$ and allergies with 5 (2\%) were equally frequent in both genders.

The most frequent psychological symptom at the high level was found in increased alcohol consumption with 29 (12\%) and the least frequent was the overwhelming need to run and hide with 2 (1\%). The most frequent psychological symptoms in the female gender were: feeling anxious and increased alcohol consumption with 23 (10\%), increased cigarette consumption, feeling depressed and a strong desire to cry with 18 (7\%), angry outbursts with 17 (7\%), inability to concentrate, easily startled and nightmares with 11 (4\%), increased consumption of tranquilizers and an over whelming need to move constantly with $6(3 \%)$, nervous tics with 5 (2\%) and an overwhelming need to run and hide with $2(1 \%)$. The most frequent psychological symptoms in the female gender were: feeling tied down with 11 (4\%), nervous laughter, stuttering and the urge to eat constantly with 5 (2\%); the accident proneness symptom with 5 (2\%) was equally frequent in both genders.

Of the 109 (46\%) showing medium chronic stress levels, 77 (32\%) were women and 32 (13\%) men. The most frequent physical symptom was neck and back pain with 90 (38\%) and the least frequent were: tremors, cold hands and feet and teeth grinding with 18 (7\%). The most frequent physical symptoms among the female gender were: neck and back pain with 61 (26\%), stomachache and frequent colds with 57 (24\%), dry-mouth with 55 (23\%), stress-related headaches with 45 (19\%), gastritis with 43 (18\%), colitis with 42 (18\%), weakness-dizziness with 39 (16\%), frequent need to urinate, loss of appetite and constipation with 33 (14\%), fatigue with 29 (12\%), migraine with 28 (12\%), high blood pressure with 27 (11\%), indigestion and clenched jaw with 22 (9\%), increased heart rate with 21 (9\%), allergies with 19 (8\%), teeth grinding with 18 (7\%) and cold hands and feet with 17 (7\%); the most frequent such symptom in men was excessive sweating with 35 (15\%).

The most frequent psychological symptom at the medium level was increased daily cigarette consumption with 68 (29\%), while the least frequent was increased consumption of tranquilizers with 5 (2\%). The female gender showed more frequency in all psychological symptoms: increased cigarette consumption with 60 (25\%), strong desire to cry with 48 (20\%), increased alcohol consumption with 46 (19\%), urge to eat constantly and angry outbursts with 45 (19\%), feeling depressed with 44 (18\%), feeling anxious with 39 (16\%), inability to concentrate and insomnia with 34 (14\%), easily startled with 28 (12\%), nervous laughter and nightmares with 27 (11\%), stuttering with $22(9 \%)$, overwhelming need to run and hide with $20(8 \%)$, increased consumption of tranquilizers and accident proneness with 12 (5\%), except for the symptoms of feeling tied down with 28 (11\%), an overwhelming need to move constantly with $16(8 \%)$ and nervous tics with $12(5 \%)$ that were equally frequent in both genders.

The low chronic stress population consisted of 94 (40\%) of whom 19 (8\%) were women and 75 (32\%) men. The most frequent physical symptom among them was indigestion with 51 (21\%) and the least frequent high blood pressure with $2(1 \%)$. The female gender displayed a greater frequency of physical symptoms: fatigue and loss of appetite with $14(6 \%)$, colitis and weakness-dizziness with 13 (6\%), frequent need to urinate with 12 (5\%), constipation with 7 (3\%); while the male gender showed a greater frequency of the symptoms of: indigestion with $32(13 \%)$, neck and back pain with $25(11 \%)$, dry-mouth with $23(10 \%)$, stress-related headaches with 19 (8\%), neck and back pain with 18 (7\%), increased heart rate with $14(6 \%)$, allergies and frequent colds with $13(5 \%)$, excessive sweating with 12 (5\%), gastritis with 9 (4\%), teeth grinding, clenched jaw and cold hands and feet with 6 (3\%) and high blood pressure with $2(1 \%)$.

The most frequent psychological symptom at the low level was angry outbursts with $38(14 \%)$, and the least frequent the overwhelming need to run and hide with 2 (1\%). The most frequent psychological symptoms among the female gender were: strong desire to cry with 19 (8\%), nervous laughter with 18 (7\%), insomnia, easily startled and increased cigarette consumption with 13 (5\%), increased alcohol consumption with 12 (5\%), and the urge to eat constantly with 6 (3\%) while the most frequent psychological symptoms among the male gender were: inability to concentrate with 18 (7\%), nervous tics with 17 (7\%), stuttering and overwhelming need to move constantly with 12 (5\%), feeling depressed, feeling tied down and accident proneness with 7 (3\%), feeling anxious and nightmares with 6 (3\%). The symptoms of angry outbursts with 19 (8\%) and overwhelming need to run and hide were equally frequent in both genders. 
An itemized description of the data according to chronic stress levels and psychological symptoms are shown in Table 1, and physical symptoms in Table 2.

\subsection{Analysis of the Association of High Level Chronic Stress with Psychophysiological Symptoms (SSI) and Gender}

The variables showing significant association in the association analysis of chronic stress according to OR and

Table 1. Distribution of chronic stress levels and physiological symptoms (SSI).

\begin{tabular}{|c|c|c|c|c|c|c|c|}
\hline \multirow{3}{*}{$\begin{array}{c}\text { Frequency of Psychological Chronic } \\
\text { Stress Symptoms }\end{array}$} & \multicolumn{3}{|c|}{ Chronic Stress Levels } & \multirow{3}{*}{$\begin{array}{c}\text { Frequency of Psychological Chronic } \\
\text { Stress Symptoms }\end{array}$} & \multicolumn{3}{|c|}{ Chronic Stress Levels } \\
\hline & \multirow{2}{*}{$\frac{\text { High }}{\mathrm{n}}$} & \multirow{2}{*}{$\begin{array}{c}\text { Medium } \\
\mathrm{n}\end{array}$} & \multirow{2}{*}{$\begin{array}{c}\text { Low } \\
\mathrm{n}\end{array}$} & & \multirow{2}{*}{$\begin{array}{c}\text { High } \\
\mathrm{n}\end{array}$} & \multirow{2}{*}{$\begin{array}{c}\text { Medium } \\
\mathrm{n}\end{array}$} & \multirow{2}{*}{$\begin{array}{c}\text { Low } \\
\mathrm{n}\end{array}$} \\
\hline & & & & & & & \\
\hline \multicolumn{4}{|c|}{ Feeling depressed } & \multicolumn{4}{|c|}{ Feeling anxious } \\
\hline Low & 10 & 16 & 47 & Low & 0 & 46 & 50 \\
\hline Medium & 0 & 48 & 34 & Medium & 6 & 23 & 35 \\
\hline High & 22 & 45 & 13 & High & 28 & 40 & 9 \\
\hline \multicolumn{4}{|c|}{ Angry outbursts } & \multicolumn{4}{|c|}{ Urge to eat constantly } \\
\hline Low & 0 & 38 & 36 & Low & 23 & 13 & 47 \\
\hline Medium & 6 & 25 & 20 & Medium & 6 & 45 & 41 \\
\hline High & 28 & 46 & 38 & High & 5 & 51 & 6 \\
\hline \multicolumn{4}{|c|}{ Overwhelming need to run and hide } & \multicolumn{4}{|l|}{ Insomnia } \\
\hline Low & 27 & 52 & 80 & Low & 11 & 27 & 49 \\
\hline Medium & 5 & 36 & 12 & Medium & 6 & 46 & 26 \\
\hline High & 2 & 21 & 2 & High & 17 & 41 & 19 \\
\hline \multicolumn{4}{|c|}{ Strong desire to cry } & \multicolumn{4}{|c|}{ Increased consumption of tranquilizers } \\
\hline Low & 5 & 21 & 50 & Low & 28 & 103 & 92 \\
\hline Medium & 6 & 27 & 17 & Medium & 0 & 1 & 2 \\
\hline High & 23 & 61 & 27 & High & 7 & 5 & 0 \\
\hline \multicolumn{4}{|c|}{ Inability to concentrate } & \multicolumn{4}{|c|}{ Increased alcohol consumption } \\
\hline Low & 0 & 24 & 38 & Low & 0 & 21 & 61 \\
\hline Medium & 16 & 45 & 26 & Medium & 5 & 40 & 14 \\
\hline High & 18 & 40 & 30 & High & 29 & 48 & 19 \\
\hline \multicolumn{4}{|c|}{ Feeling tied down } & \multicolumn{4}{|c|}{ Nightmares } \\
\hline Low & 0 & 40 & 76 & Low & 6 & 47 & 64 \\
\hline Medium & 17 & 41 & 10 & Medium & 12 & 35 & 37 \\
\hline High & 17 & 56 & 8 & High & 16 & 27 & 6 \\
\hline \multicolumn{4}{|c|}{ Nervous tics } & \multicolumn{4}{|c|}{ Increased cigarette consumption } \\
\hline Low & 23 & 68 & 58 & Low & 0 & 16 & 42 \\
\hline Medium & 6 & 29 & 3 & Medium & 5 & 25 & 32 \\
\hline High & 5 & 24 & 29 & High & 29 & 68 & 20 \\
\hline Easily startl & & & & Accident pron & ess & & \\
\hline Low & 11 & 58 & 56 & Low & 24 & 78 & 87 \\
\hline Medium & 12 & 23 & 25 & Medium & 0 & 18 & 0 \\
\hline High & 5 & 28 & 13 & High & 10 & 13 & 7 \\
\hline Nervous laug & & & & Overwhelming need to $\mathrm{m}$ & ve cons & antly & \\
\hline Low & 17 & 45 & 55 & Low & 23 & 81 & 79 \\
\hline Medium & 12 & 37 & 21 & Medium & 5 & 12 & 3 \\
\hline High & 5 & 27 & 18 & High & 6 & 32 & 13 \\
\hline Stuttering & & & & & & & \\
\hline Low & 18 & 60 & 45 & & & & \\
\hline Medium & 11 & 26 & 27 & & & & \\
\hline High & 5 & 22 & 18 & & & & \\
\hline
\end{tabular}

Source: data tabulated by the authors. 
Table 2. Distribution of chronic stress levels and physical symptoms (SSI).

\begin{tabular}{|c|c|c|c|c|c|c|c|}
\hline \multirow{3}{*}{$\begin{array}{c}\text { Frequency of Physical Chronic Stress } \\
\text { Symptoms }\end{array}$} & \multicolumn{3}{|c|}{ Chronic Stress Levels } & \multirow{3}{*}{$\begin{array}{c}\text { Frequency of Physical Chronic } \\
\text { Stress Symptoms }\end{array}$} & \multicolumn{3}{|c|}{ Chronic Stress Levels } \\
\hline & High & Medium & Low & & High & Medium & Low \\
\hline & $\mathrm{n}$ & $\mathrm{n}$ & $\mathrm{n}$ & & $\mathrm{n}$ & $\mathrm{n}$ & $\mathrm{n}$ \\
\hline \multicolumn{4}{|c|}{ Increased heart rate } & \multicolumn{4}{|c|}{ Stomachache } \\
\hline Low & 12 & 40 & 46 & Low & 0 & 24 & 61 \\
\hline Medium & 5 & 41 & 28 & Medium & 5 & 22 & 7 \\
\hline High & 17 & 28 & 20 & High & 29 & 63 & 26 \\
\hline \multicolumn{4}{|l|}{ Dry-mouth } & \multicolumn{4}{|c|}{ Neck and back pain } \\
\hline Low & 18 & 29 & 42 & Low & 0 & 5 & 29 \\
\hline Medium & 5 & 6 & 28 & Medium & 0 & 23 & 27 \\
\hline High & 11 & 74 & 24 & High & 34 & 81 & 38 \\
\hline \multicolumn{4}{|c|}{ Weakness-dizziness } & \multicolumn{4}{|c|}{ Loss of appetite } \\
\hline Low & 6 & 14 & 49 & Low & 7 & 23 & 49 \\
\hline Medium & 12 & 40 & 27 & Medium & 1 & 52 & 26 \\
\hline High & 16 & 55 & 18 & High & 26 & 34 & 21 \\
\hline \multicolumn{4}{|l|}{ Fatigue } & \multicolumn{4}{|c|}{ Constipation } \\
\hline Low & 6 & 22 & 31 & Low & 6 & 33 & 59 \\
\hline Medium & 6 & 58 & 36 & Medium & 11 & 35 & 22 \\
\hline High & 22 & 29 & 27 & High & 17 & 41 & 13 \\
\hline \multicolumn{4}{|c|}{ Teeth grinding } & \multicolumn{4}{|c|}{ Frequent colds } \\
\hline Low & 9 & 63 & 77 & Low & 6 & 17 & 49 \\
\hline Medium & 5 & 24 & 11 & Medium & 6 & 23 & 25 \\
\hline High & 20 & 18 & 6 & High & 22 & 69 & 20 \\
\hline \multicolumn{4}{|c|}{ Clenched jaw } & \multicolumn{4}{|c|}{ Cold hands and feet } \\
\hline Low & 12 & 58 & 80 & Low & 11 & 90 & 81 \\
\hline Medium & 0 & 29 & 8 & Medium & 11 & 1 & 2 \\
\hline High & 22 & 22 & 6 & High & 12 & 18 & 11 \\
\hline \multicolumn{4}{|c|}{ Stress-related headaches } & \multicolumn{4}{|c|}{ Allergies } \\
\hline Low & 5 & 30 & 26 & Low & 12 & 49 & 74 \\
\hline Medium & 12 & 29 & 42 & Medium & 12 & 41 & 1 \\
\hline High & 17 & 50 & 26 & High & 10 & 19 & 19 \\
\hline \multicolumn{4}{|l|}{ Migraine } & \multicolumn{4}{|c|}{ Gastritis } \\
\hline Low & 23 & 57 & 71 & Low & 12 & 30 & 70 \\
\hline Medium & 0 & 21 & 23 & Medium & 11 & 7 & 18 \\
\hline High & 11 & 33 & 0 & High & 11 & 54 & 10 \\
\hline \multicolumn{4}{|c|}{ Excessive sweating } & \multicolumn{4}{|c|}{ Colitis } \\
\hline Low & 17 & 54 & 67 & Low & 12 & 48 & 70 \\
\hline Medium & 12 & 38 & 10 & Medium & 6 & 7 & 8 \\
\hline High & 5 & 63 & 17 & High & 16 & 54 & 16 \\
\hline Frequent need to & hate & & & High blood & ssure & & \\
\hline Low & 6 & 61 & 57 & Low & 6 & 42 & 91 \\
\hline Medium & 5 & 15 & 17 & Medium & 17 & 23 & 1 \\
\hline High & 23 & 33 & 20 & High & 11 & 34 & 2 \\
\hline Tremors & & & & Indiges & & & \\
\hline Low & 12 & 63 & 86 & Low & 6 & 37 & 42 \\
\hline Medium & 11 & 24 & 8 & Medium & 12 & 42 & 20 \\
\hline High & 11 & 18 & 0 & High & 16 & 30 & 51 \\
\hline
\end{tabular}

Source: data tabulated by the authors. 
with IC 95\% as well as $\mathrm{p}<0.05$ were: nightmares, feeling anxious, loss of appetite, increased alcohol consumption, clenched jaw, teeth grinding, increased consumption of tranquilizers, increased cigarettes consumption, stomachaches, angry outbursts, feeling depressed, frequent need to urinate, tremors, neck and back pain, felling tied down, accident proneness, cold hands and feet, increased heart rate, constipation, strong desire to cry, insomnia and frequent colds.

Later a binary linear regression analysis was applied in which confounding factors were controlled and the strength of association was assessed by adjusted OR and with CI 95\% well as p $<0.05$. It was found that only the female gender and the stress symptoms of: constipation, frequent colds, cold hands and feet, fatigue and high blood pressure maintained a significant association with high level chronic stress as seen in Table 3.

\subsection{Predictive Value of SSI with Psychophysiological Symptoms of Chronic Stress and Gender}

Table 4 shows the correlations between SSI scores and the variables of this study, showing moderate positive correlations (Pearson's $r>0.30$ and $p=0.05$ ) that were: female gender, fatigue, frequent colds, cold hands and feet and insomnia. The high blood pressure symptom was not considered for this study because of the low or null correlation with Pearson's $\mathrm{r}<0.30$.

The correlation coefficients obtained in the step regression analysis for high level chronic stress and assessed with SSI, with each of the psychophysiological symptoms as well as gender that fulfilled the prediction criteria

Table 3. Association between high level chronic stress and psychophysiological symptoms (SSI) and gender, by adjusted OR.

\begin{tabular}{ccccc}
\hline & High Level Stress & & \\
\hline & & & OR & \\
\hline Variables & $\mathbf{n}$ & $\mathbf{P}$ & Adjusted & IC 95\% \\
\hline $\begin{array}{c}\text { Female gender } \\
\text { Physical symptoms }\end{array}$ & 23 & $0.04^{*}$ & 2.38 & $1.10-3.23$ \\
Fatigue & & & \\
Constipation & 22 & $0.04^{*}$ & $0.04^{*}$ & $1.27-16.6$ \\
Frequent colds & 17 & $0.00^{* *}$ & $0.00^{* *}$ & $2.22-25.6$ \\
Cold hands and feet & 12 & $0.00^{* *}$ & $0.00^{* *}$ & $1.58-7.71$ \\
Psychological symptoms & 29 & $0.00^{* *}$ & $0.00^{* *}$ & $1.05-24.7$ \\
$\quad$ Insomnia & 17 & & & \\
\hline
\end{tabular}

Source: data tabulated by the authors.

Table 4. Correlation matrix between the psychophysiological symptoms scores, gender and chronic stress (SSI).

\begin{tabular}{|c|c|c|c|c|c|c|}
\hline & Chronic & & Female & Frequent & & Cold \\
\hline & Stress & Insomnia & Gender & Colds & Fatigue & Hands-fee \\
\hline \multicolumn{7}{|l|}{ Chronic } \\
\hline Stress & ------ & & & & & \\
\hline Insomnia & $0.36^{* *}$ & ------ & & & & \\
\hline Female gender & $0.51^{* *}$ & $0.38^{* *}$ & ------ & & & \\
\hline Frequent colds & $0.43^{*}$ & $0.27^{* *}$ & $0.17^{* *}$ & ------ & & \\
\hline Fatigue & $0.44^{*}$ & $0.44^{* *}$ & $0.50^{* *}$ & $0.23^{* *}$ & ------ & \\
\hline Cold hands-feet & $0.40^{* *}$ & $0.23^{* *}$ & $0.14^{* *}$ & $0.20^{* *}$ & $0.06^{*}$ & ------ \\
\hline
\end{tabular}

Source: data tabulated by the authors. 
and with significant value revealed that working, digestive problems, isolation from others, nail-biting and depression were predictors of the model $\left(\mathrm{R}^{2}=0.69 ; \mathrm{F}=16.0, \mathrm{p}<0.01\right)$. The regressive model included the following; SSI $=0.41$ (fatigue) +0.23 (female gender) +0.54 (frequent colds) +0.49 (insomnia) +0.40 (cold hands and feet) significantly increasing the percentage explained by SSI. These data are seen in Table 5.

\section{Discussion}

Previous studies about stress in immigrants have already shown its presence in the immigrant population [3] [5] [8]. This study showed the existence of a significant association according to the adjusted OR between high level chronic stress and the female gender as well as some psychophysiological symptoms. The physical symptoms showing association were: fatigue, frequent colds and cold hands and feet while the only psychological symptom showing association was insomnia. There was a positive correlation given that the index indicated a dependency between the high level chronic stress and the female gender and psychophysiological symptoms; i.e. when one of them increases so do the others.

Studies have already reported the female gender as the group most vulnerable to high levels of stress [17] [18]. It is known that Mexican immigrant women come from a culture where gender stereotypes are still very much in effect with a level of inequality between men and women. Female immigrants very often have abilities and capacity above average in their countries, with higher education and they possess great initiative and strength. When they emigrate, they suffer from a dramatic decline in social class, are relegated to work stereotyped as for women, discredited and invisible, such as maids or in cleaning, caring for dependent people or in prostitution [18]-[20], all of which lead to high levels of stress.

The results suggest that chronic stress plays an important role in the risk of disease with the presence of manifest psychophysiological symptoms: constipation, frequent colds, cold hands and feet, fatigue and insomnia among Mexican immigrants and that both male and female immigrants have different physiological responses [16], making the immigrant population as a group vulnerable to stress.

Different studies have said that the most common symptoms are: fatigue, depression, anxiety, insomnia, headaches and high blood pressure [9] [20]-[23]. These results coincide only with the symptoms of fatigue and insomnia as mentioned above. The difference in symptoms may be due to the fact that those studies are about different populations and countries as well as other stress-related symptomology such as behavioral changes at a general level, employment and alteration of physical functions and at the psychological, emotionally disturbed and psychosomatic levels [21] [23]-[26].

Our investigation also showed a greater frequency of medium level chronic stress, considered a red-flag situation because if there is no intervention strategy aimed at lowering medium stress levels to low, they could increase to high levels at any time.

It is essential to take into account the high levels of chronic stress in Mexican immigrants found in this investigation and the manifest psychophysiological symptoms causing them because they may influence factors related to the work they perform [4] [9].

Table 5. Hierarchical multiple regression analysis of high level chronic stress with psychophysiological symptoms of fatigue, constipation, frequent colds, insomnia, hand hands and feet and gender.

\begin{tabular}{|c|c|c|c|c|c|c|}
\hline & Correlation & & & & & \\
\hline REGRESSION & Pearson's & & & & & \\
\hline MODEL & $\mathbf{r}$ & Beta & $\mathbf{E E}$ & $\mathbf{F}$ & $p$ & $\mathbf{R}^{2}$ \\
\hline Constant & & 0.401 & & 16 & & 0.69 \\
\hline 1 fatigue & $0.44^{* *}$ & 0.305 & 0.045 & & $<0.01$ & \\
\hline 2 Female gender & $0.51^{* *}$ & 0.21 & 0.042 & & $<0.01$ & \\
\hline 3 Frequent colds & $0.43^{* *}$ & 0.287 & 0.04 & & $<0.01$ & \\
\hline 4 Insomnia & $0.36^{* *}$ & 0.209 & 0.049 & & $<0.01$ & \\
\hline 5 Cold hands-feet & $0.40^{* *}$ & 0.256 & 0.059 & & $<0.01$ & \\
\hline
\end{tabular}

Chronic stress and its psychophysiological symptoms. SSI Questionnaire. ${ }^{* *}$ Significant correlation $p<0.01$. Source: data tabulated by the authors. 


\section{Limitations}

The strengths of this study, among others, include having a representative sample. It is also important to mention the limitations of this study, mainly the existence of other factors that may have influenced chronic stress at the time the questionnaires were applied, such as social, economic and cultural traits that were not considered in the study.

\section{Conclusion}

In conclusion, Mexican immigrant women living in Edmonton, Canada who state that they have felt: fatigue, constipation, frequent colds, cold hands and feet and insomnia are more at risk to having high level chronic stress in comparison with men. Early detection of the most common symptoms of chronic stress may help promote and implement programs aimed at prevention to eliminate and/or control said symptoms before they affect their health and occupational safety.

\section{References}

[1] Patiño, C. and Kirchner, T. (2010) Stress and Psychopathology in Latin-American Immigrants: The Role of Coping Strategies. Psychopathology, 43, 17-24. http://dx.doi.org/10.1159/000255959

[2] Mueler, R.E. (2005) Mexican Immigrants and Temporary Residents in Canada: Current Knowledge and Future Research. Migraciones Internacionales, 3, 1-26. http://www.redalyc.org/articulo.oa?id=15103102

[3] Negy, C., Hammons, M., Reig-Ferrer, A. and Carper, T. (2010) The Importance of Addressing Acculturative Stress in Marital Therapy with Hispanic Immigrant Women. International Journal of Clinical Health Psychology, 10, 5-21.

[4] Cervantes, C.R., Padilla, M.A., Napper, E.L. and Goldbach, T.J. (2013) Acculturation-Related Stress and Mental Health Outcomes among Three Generations of Hispanic Adolescents. Hispanic Journal of Behavioral Sciences, 1, 218. http://dx.doi.org/10.1177/0739986313500924

[5] Al-Baldawi, R. (2002) Migration-Related Stress and Psychosomatic Consequences. International Congress Series, 1241, 271-278. http://dx.doi.org/10.1016/S0531-5131(02)00649-0

[6] Vasquez, J.M. (2013) Mexican Americans across Generations: Immigrant Families, Racial Realities. American Journal of Sociology, 118, 1450-1452.

[7] Trickett, E.J. (1996) Future for Community Psychology: The Contexts of Diversity and the Diversity of Contexts. American Journal of Community Psychology, 24, 209-234. http://dx.doi.org/10.1007/BF02510399

[8] Ramírez, G.J. (2012) Mental Health Care for Latino Immigrants in the U.S.A. and the Quest for Global Health Equities. Psychosocial Intervention, 21, 305-318. http://dx.doi.org/10.5093/in2012a27

[9] McClure, H., Snodgrass, J., Martinez, C., Eddy, J., Jiménez, R. and Isiordia, L. (2010) Discrimination, Psychosocial Stress, and Health among Latin American Immigrants in Oregon. American Journal of Human Biology, 22, 421-423. http://dx.doi.org/10.1002/ajhb.21002

[10] Castro, S.A. (2011) Acculturation Strategies and Psychological and Sociocultural Adaptation of Foreign Students in Argentina. Interdisciplinaria, 28, 115-130.

[11] Spitzer, D. (2009) Stress, Migration, Gender y Type 2 Diabetes. Department of Anthropology, University of Alberta, 1-12. www.researchgate.net/publication/255600388_Stress_Migration_Gender_Type_2_Diabetes

[12] Lazarus, R. (1966) Psychological Stress and the Coping Process. McGraw-Hill, New York.

[13] Murillo, M. and Molero, A. (2012) Factores psicosociales asociados al bienestar de inmigrantes de origen colombiano en España. Psychosocial Intervention, 21, 319-329. http://dx.doi.org/10.5093/in2012a28

[14] Segredo, P., Veloso, P. and Rodríguez, S. (2004) Stress, Behavior in Primary Health Care. Revista Cubana de Medicina General Integral, 20, 2-8.

[15] Lwanga, S.K. and Lameshow, S. (1991) Sample Size Determination in Health Studies. World Health Organization, Geneva. www.whqlibdoc.who.int/publications/9241544058 (p1-p22).pdf

[16] Lipp, M. and Guevara, A. (1994) Empirical Validation of the Stress Symptoms Inventory (SSI). Estudios de Psicología, 11, 43-49.

[17] Magalhaes, L., Carrasco, C. and Gastaldo, D. (2010) Undocumented Migrants in Canada: A Scope Literature Review on Health, Access to Services, and Working Conditions. Journal of Immigrant and Minority Health, 12, 132-151. http://dx.doi.org/10.1007/s10903-009-9280-5

[18] Pérez, G.M. (2008) Migrant Women: Realities, Stereotypes and Educational Prospects. Revista Española de Educación Comparada, 14, 137-175. 
[19] Capel, H. (1997) Los Inmigrantes en la ciudad. Economic Growth, Innovation and Social Conflict. Revista Electrónica de Geografía y Ciencias Sociales, 3, 2-34.

[20] Olesen, K., Carneiro, I., Jørgensen, M., Rugulies, R., Rasmussen, C., Søgaard, K. and Flyvholm, M. (2012) Associations between Psychosocial Work Environment and Hypertension among Non-Western Immigrant and Danish Cleaners. International Archives of Occupational and Environmental Health, 85, 829-835. http://dx.doi.org/10.1007/s00420-011-0728-2

[21] Donlan, W. and Junghee, L. (2010) Courage, Nerves, and Scare: Culture-Bound Syndromes and Mental Health among Mexican Migrants in the United States. Advances in Mental Health, 9, 288-302. http://dx.doi.org/10.5172/jamh.9.3.288

[22] Breslau, J., Borges, G., Tancredi, D., Saito, N., Anderson, H., Kravitz, R. and Mora, M. (2011) Health Selection among Migrants from Mexico to the US: Childhood Predictors of Adult Physical and Mental Health. Public Health Reports, 126, 361-370.

[23] Iwata, M., Ota, K.T. and Duman, R.S. (2013) The Inflammasome: Pathways Linking Psychological Stress, Depression, and Systemic Illnesses. Brain, Behavior and Immunity, 31, 105-114. http://dx.doi.org/10.1016/j.bbi.2012.12.008

[24] Cervantes, R. (2012) Using Qualitative Methods for Revising Items in the Hispanic Stress Inventory. Hispanic Journal of Behavioral Sciences, 34, 208-231. http://dx.doi.org/10.1177/0739986312442495

[25] Hjellset, V., Ihlebæk, C., Bjørge, B., Eriksen, H. and Høstmark, A. (2011) Health-Related Quality of Life, Subjective Health Complaints, Psychological Distress and Coping in Pakistani Immigrant Women with and without the Metabolic Syndrome. Journal of Immigrant and Minority Health, 13, 732-741. http://dx.doi.org/10.1007/s10903-010-9409-6

[26] Salonius, P. (2013) Population Growth in the United States and Canada: A Role for Scientists. The Social Contract Journal, 23, 16-17. http://www.thesocialcontract.com/artman2/publish/tsc_23_3/tsc_23_3_salonius.shtml

\section{Submit or recommend next manuscript to SCIRP and we will provide best service for you:}

Accepting pre-submission inquiries through Email, Facebook, Linkedin, Twitter, etc A wide selection of journals (inclusive of 9 subjects, more than 200 journals)

Providing a 24-hour high-quality service

User-friendly online submission system

Fair and swift peer-review system

Efficient typesetting and proofreading procedure

Display of the result of downloads and visits, as well as the number of cited articles

Maximum dissemination of your research work

Submit your manuscript at: http://papersubmission.scirp.org/ 